This is the peer reviewed version of the following article: Pelle, M., Das, A. A. K., Madden, L. A., Paunov, V. N., Bioimprint Mediated Label-Free Isolation of Pancreatic Tumor Cells from a Healthy Peripheral Blood Cell Population. Adv. Biosys. 2020, 2000054, which has been published in final form at doi.org/10.1002/adbi.202000054. This article may be used for non-commercial purposes in accordance with Wiley Terms and Conditions for self-archiving.

\title{
Bioimprint mediated label-free isolation of pancreatic tumor cells from a healthy peripheral blood cell population
}

\author{
Marie Pelle, Anupam A.K. Das, Leigh A. Madden, Vesselin N. Paunov* \\ M. Pelle, Dr A.A.K. Das, Prof V. N. Paunov \\ Department of Chemistry and Biochemistry \\ University of Hull \\ Hull, HU6 7RX, United Kingdom \\ Email: V.N.Paunov@hull.ac.uk \\ Dr. L.A. Madden \\ Department of Biomedical Sciences \\ University of Hull \\ Hull, HU6 7RX, United Kingdom
}

Keywords: pancreatic cancer, early diagnosis, bioimprint, tumor cell separation, liquid biopsies

\begin{abstract}
New techniques are required for earlier diagnosis and response to treatment of pancreatic cancer. Here we report a label-free approach in which circulating pancreatic tumor cells are isolated from healthy peripheral blood cells via cell bioimprinting technology. The method involves pre-fabrication of pancreatic cell layers and a sequential casting the cell surfaces with series of custom-made resins to produce negative cell imprints. The imprint functionalized with a combination of polymers to engineer a weak attraction to the cells which is further amplified by the increased area of contact with the matching cells. A flow-through bioimprint chip was designed and tested for selectivity towards two pancreatic tumor cell lines, ASPC-1 and Mia-PaCa-2. Healthy human peripheral blood mononuclear cells (PBMCs) were spiked with pancreatic tumor cells at various concentrations. Bioimprints were designed for preferential retention of the matching pancreatic tumor cells and with respect to PBMCs. Tumor bioimprints were capable of capturing and concentrating pancreatic tumor cells from a mixed cell population with increased retention observed with the number of seedings. ASPC-1 bioimprints preferentially retained both types of pancreatic tumor cells. This technology could have relevance to collection and interrogation of liquid biopsies, early detection and relapse monitoring of patients with pancreatic cancer.
\end{abstract}

\section{Introduction}

Patients diagnosed with pancreatic cancer will most likely die within a year irrespective of treatment [1,2]. It has the lowest survival by stage of any other solid tumor [3]; a 10-year prospective study reported only 27/196 patients survived beyond 1 year and only a single 
non-surgically resected patient survived beyond 5 years [4]. A comprehensive review of 37,000 hospital cases of PC has also shown overall survival of only $0.41 \%$ [4]. This high mortality is mainly because of the propensity of the tumor to early metastasize and spread [5] and even the smallest primary lesions often show perineural and lympho-vascular invasion [6]. More recently, the 5-year survival rates have improved slightly but differs from country to country, based on management approaches such as early surgical removal, stage, absence of lymph node metastasis. Worldwide, survival is generally around 5\% [2] and it is the fifth most common cause of cancer death in the UK [7] and Europe [8]. In the U.S, PC is the fourth leading cause of cancer death [9] and second most common gastrointestinal malignancy. Surgical resection of the tumor is associated with the best patient outcomes but as stated above due to early tumor spread this is not an option in many cases.

Pancreatic cancer is a malignancy that is very difficult to detect early, it is rarely cured (less than $1 \%$ ) and even small tumors have often metastasized early to the liver [10]. This is preceded by release of circulating tumor cells (CTCs) which spread to the patients organs through the peripheral blood circulatory system $[11,49]$. Pancreatic CTCs can be used as a biomarker for potential earlier detection of cancer [12] however, there is no proven technology which could capture and detect these cells [12-14]. CTCs usually have oval shapes within the blood and there are size and shape differences between the pancreatic tumor cells and normal blood cells, which allows the latter to be selectively targeted by cell shape recognition. These features may potentially allow pancreatic CTCs to be extracted from blood samples by cell shape and size recognition using bioimprints produced for these specific types of cells. Available methods for the collection or detection of CTCs take advantage of various physical properties of the target cells and their surfaces [15-24].

Bioimprints have recently been recognized for their great potential for biomedical diagnostics and targeted therapies as they can effectively capture cells of specific shape and morphology, 
isolating them or delivering biocides directly to their surface [25-27]. Bioimprints are exact physical copies of the surface of a cell layer which can be produced by impressing the cells with a layer of curable polymer or other material [25, 27-29]. The bioimprinting process produces a polymeric cast of the whole cell layer, producing a negative replica of the cells shape and size $[25,28,29,50]$. When a matching cell comes in contact with the bioimprint, it becomes strongly attracted to its surface, as the bioimprint-cell attraction is amplified by the increased contact area which results in cell shape and size recognition [30]. Dickert et al.[31] pioneered a soft lithographic technique by imprinting whole yeast cells on the sensor surface of a quartz crystal microbalance (QCM) which allowed selective capture of different types of yeast. Similar approaches have been recently developed for detection of bioparticles [32], viruses [33], bacteria [34] and human cells [35]. Bioimprint binding of rod-like and oval-like shaped bacteria has also been demonstrated [36]. More complex techniques [37] involved a combination of cell-imprints combined with affinity ligands to trap microorganisms by simultaneous shape/size recognition and surface affinity. Whole cell imprinting has gained traction for development of specific probes for concentration and identification of microorganisms in aqueous samples [34,38]. Jenik and co-workers [39] reported blood cell bioimprints that allowed identification of different blood groups.

Recently, bioimprinting technology was developed to produce colloid antibodies, which use cell shape recognition to selectively target microbial cells of specific shape [26,27]. Furthermore, Das et al. [28] successfully developed bioimprinting technology to separate leukemic myeloblasts from healthy peripheral blood cells. A promising approach for targeting specific blood cancer cells and their separation from peripheral blood based on generic bioimprints has also been recently reported $[25,28,29]$. Personalized bioimprints that may have the potential to target specific cell types and do not require major morphological differences from healthy cells or express particular surface moieties. 
In the present study, we focus on developing bioimprints from pancreatic tumor cells which can selectively attract CTCs of matching shape, size and morphology. Most CTCs have an oval shape, different average size and morphology than healthy circulatory cells. The use of tumor cell bioimprints allowed for a device to be designed for concentrating and extracting tumor cells from healthy blood cell samples which could see a novel approach for collecting liquid biopsies to isolate CTCs that can then be used for early detection of pancreatic cancer.
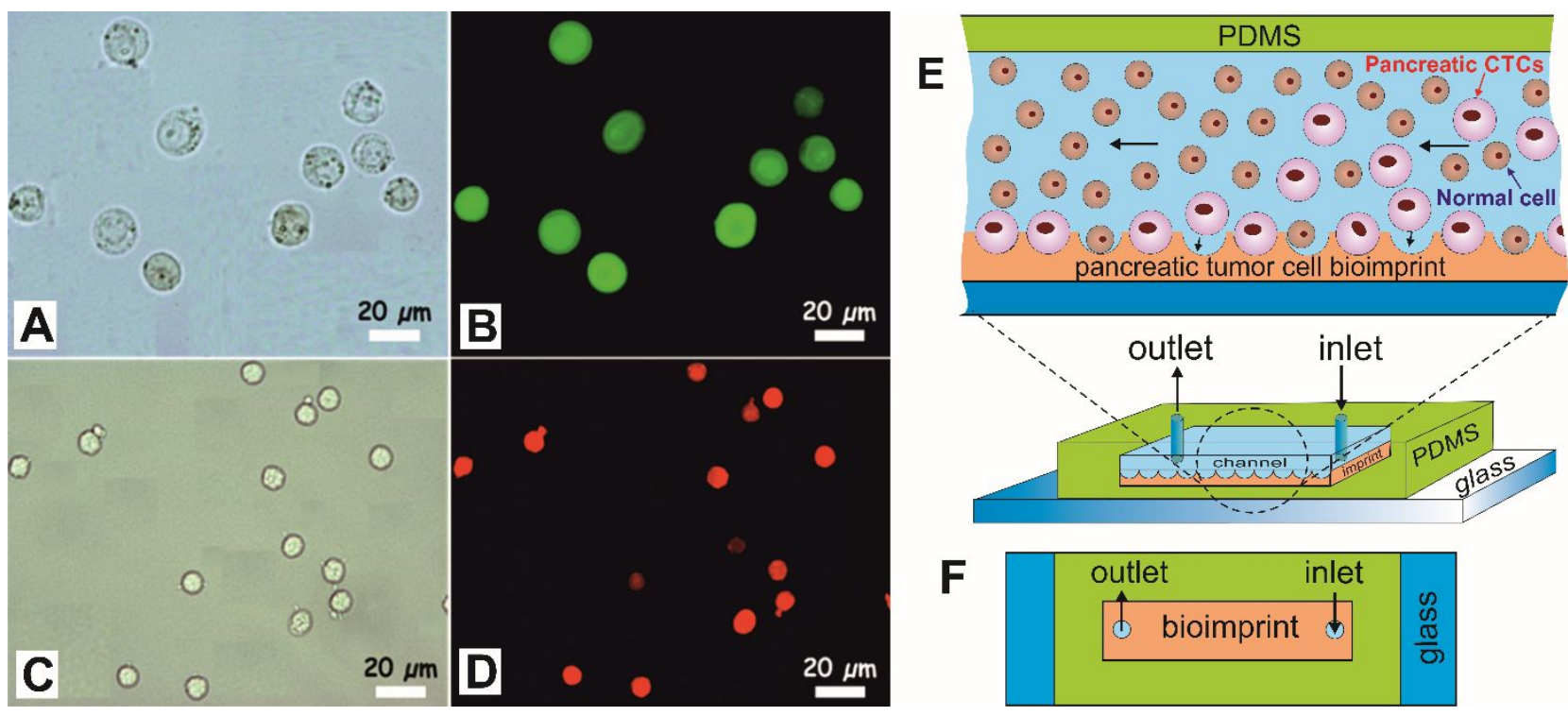

Figure 1. Optical and fluorescence microscope images of (A,B) ASPC-1 cells (pancreatic tumor cells) and (C,D) normal peripheral blood mononuclear cells (PBMCs) suspended in PBS buffer. Note that the ASPC-1 cells in suspension are all spherical in shape but differ significantly in size and morphology from the PBMCs. (E) Principle of action of our bioimprint-based device for concentrating of circulating tumor cells (CTCs) from blood samples of patients with pancreatic cancer. The bioimprint has several orders of magnitude higher selectivity to the pancreatic CTCs then for normal white blood cells based on their interaction with a bioimprinted surface. The imprint binds the CTC cells that fit closely into the casted cell shapes on its surface more strongly than the PBMCs. The cell shape recognition amplifies the CTCs attraction to the bioimprint. (F) Schematics of the bioimprint chip.

Pancreatic cancer liquid biopsies present an ideal target for cell recognition by prefabricated bioimprints where a very strong specific adhesion can occur between the bioimprint and tumor cells within a sample containing cells of matching shape. Here we investigate a novel in vitro approach for liquid biopsies based on bioimprinting technology which would potentially allow capturing and concentrating pancreatic CTCs from blood samples. The approach involved 
preparation of bioimprints of pancreatic tumor cell lines and using these to develop a device for capturing and interrogating tumor cells. The technology may potentially be used either for direct capture and interrogation of pancreatic tumor cells or monitoring of cancer progression. The bioimprint-based approach is expected to enhance the potential for providing minimally invasive contemporaneous information on tumor biology prior to each planned line of molecular treatment, as these become available. The paradigm of the liquid biopsy is already becoming clinical practice in lung cancer for the assessment of EGFR mutations. Being able to study the whole cells rather than circulating cell free DNA $[17,18]$ has great advantages as they provide a more specific picture of therapy related changes. Data obtained can shed further light into the biology of pancreatic cancer, such as the nature of stem cells and the interactivity of tumor cells with the coagulation pathway.

The extraction of tumor cells from blood is possible due to the distinct cell size and morphological differences between the pancreatic tumor cells and normal blood cells (PBMC) cf. Figure 1A,B with Figure 1C,D. The principle action of the device is illustrated in Figure $1 \mathrm{E}-\mathrm{F}$ and relies on the increased area of contact of the target cells with the bioimprinted surface upon cell shape recognition. The latter is based on amplification of the cell adhesion when the imprint surface is approached by cells of matching shape and size in near vicinity and can increase the binding energy of even a weak cell-surface attraction by several orders of magnitude. Since normal white blood cells are much smaller and different in morphology to tumor cells, this result in much higher cell shape-specific retention of the latter on the bioimprint surface. Note that the cell recognition here relies of physical cell shape and size replication rather than bio-molecular recognition based on much more expensive antibodies [25]. Rhim et al. [48] recently reported pancreatic CTCs invade and enter the bloodstream unexpectedly early, before malignancy could be detected by rigorous histologic analysis which is widely associated with epithelial-to-mesenchymal transition (EMT). Circulating pancreatic tumor cells maintain a 
mesenchymal phenotype, exhibited stem cell properties, and seeded the liver [48]. Along this line, here we explore how universal is the pancreatic tumor bioimprint fabricated using secondary tumor cells (ASPC-1) in capturing pancreatic tumor cells generated by a primary tumor of similar phenotype (Mia-PaCa-2). Preparation of a universal, generic negative bioimprint of a widely pancreatic tumor cell line would allow potential isolation of any patient CTCs of the same type and collection of liquid biopsies that may facilitate early diagnosis.
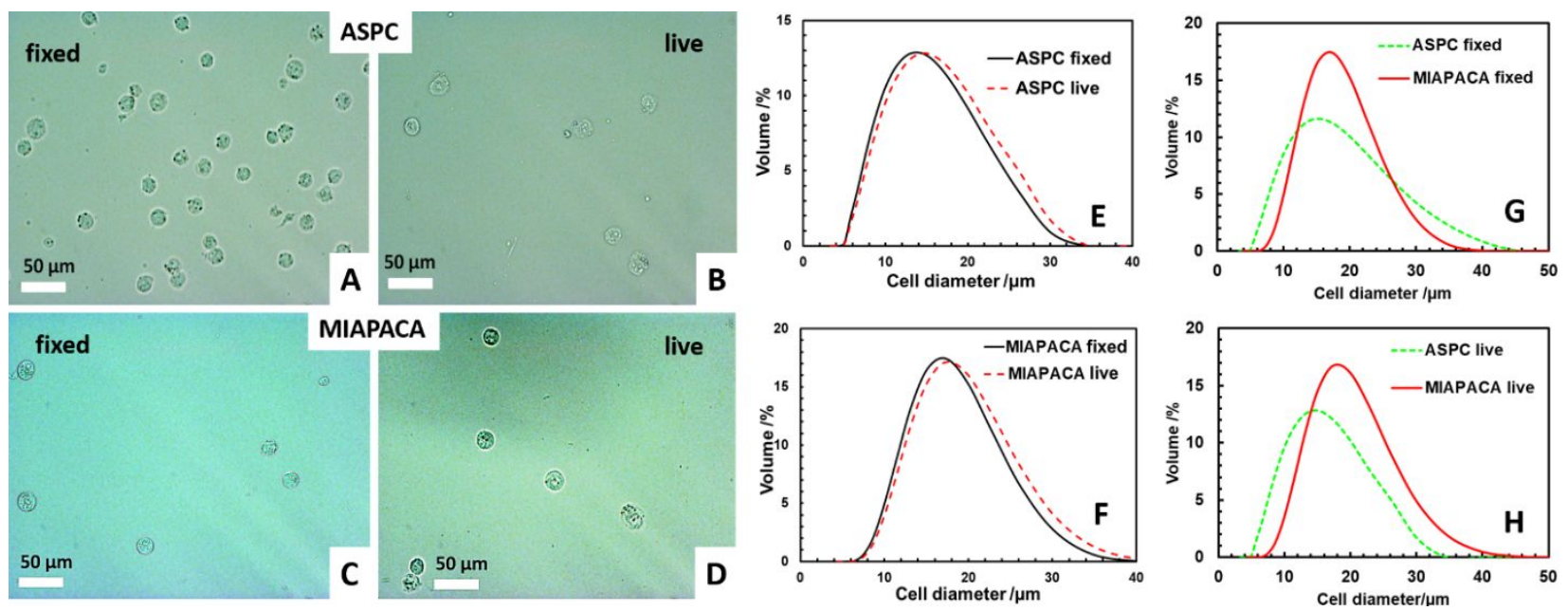

Figure 2. The effect of fixation on the tumor cell dimensions. Brightfield optical microscopy images of ASPC-1 fixed (A) and live cells (B); Mia-PaCa-2 fixed (C) and live cells (D). The cell diameter distributions were analyzed by Mastersizer before fixation (Red dashed line) and after fixation (Black line) with $0.5 \%$ glutaraldehyde (E,F). The cell size distributions of the two types of pancreatic tumor cell lines are compared in $(\mathrm{G})$ for fixed and $(\mathrm{H})$ for live cells.

\section{Results and Discussion}

\subsection{Cell fixation and staining}

In order for a bioimprint to be able to effectively distinguish and capture the cells of interest there must be a measurable size and shape difference between the target cells and other cells within a mixed cell population. Also, effective staining of the target cells is required in order to be able to quantify the capture efficiency of the bioimprints. To achieve this ASPC-1 cells were stained with carboxyfluorescein-lipid conjugate and PBMC were stained with lissamine rhodamine. Light and fluorescence microscopy showed both effective staining of ASPC-1 and PBMC and the size differences were clearly observed via microscopy (Figure 1A-D). To enable 
a high throughput and multiple repeat experiments in this exploratory study, cells were fixed prior to testing. This was done to avoid uncontrollable change of the cell morphology and size as a fraction of them may lose their viability in the course of the experiments which may affect their interactions with the bioimprints. The effect of cell fixation therefore is important in terms of potential altering of the cell dimensions. To investigate the magnitude of this effect, the cells, either live of fixed, were analyzed using a Matersizer. The data obtained suggests a negligible effect on cell dimensions after fixation, all cells were very slightly smaller (see Figure 2 and Table 1). Mia-PaCa-2 were the larger cells with a mean live cell size of (live $20.7 \mu \mathrm{m}$; fixed 18.7 $\mu \mathrm{m}$ ) then ASPC-1 (live $16.3 \mu \mathrm{m}$; fixed $16.2 \mu \mathrm{m}$ ). By comparison, PBMCs showed a mean diameter of $8.6 \mu \mathrm{m}$ for the fixed cells and $9.2 \mu \mathrm{m}$ for the live cells. All cells were normally distributed suggesting that a very little overlap exists between the pancreatic tumor cells and PBMCs in terms of cell size (see Figure 1C, D).

Table 1. Volume weighted mean diameter of fixed and live ASPC-1 and Mia-PaCa-2 cells.

\begin{tabular}{ccc} 
Type of cells & ASPC-1 & Mia-PaCa-2 \\
\hline Fixed & $16.3 \pm 1.6$ & $18.7 \pm 0.14$ \\
Live & $16.2 \pm 0.3$ & $20.7 \pm 1.3$ \\
\hline
\end{tabular}

\subsection{Bioimprint fabrication}

The protocol for fabrication of the bioimprints used is schematically presented in Figure 3A. The cell templating method is similar (but not identical) to the replication of the surface of particle monolayers in the Gel Trapping technique [40-45] and the associated fabrication of micro-lens arrays from particle monolayers [46]. The pancreatic tumor cell suspension was mixed with glucose and xanthan gum as a viscosity modifier and spread over a glass substrate pre-coated with a cationic polymer (PDAC). The role of the glucose was to fill the voids between the cells upon drying and stop the templating resin (Sylgard 184 elastomer (PDMS) or 
polyurethane (PU)) from penetrating into the voids of the cells multilayer. After curing, the PDMS negative imprint was peeled off, cleaned from any cell residues by using adhesive tape and then treated with a diluted hydroxypropyl methyl cellulose (HPMC) aqueous solution in order to form a molecular layer of adsorbed HPMC which facilitates the detachment of the further templated copies of the bioimprint [28]. Then the PDMS bioimprint was templated again with a UV curable PU resin to produce a master positive imprint on polyethylene terephthalate (PET) foil. The latter was used to create multiple identical negative imprints on PET using other resins (UV curable acrylic resins or PU resin) with HPMC treatments in between. Although our method uses cell multilayers as a starting template, the cells are pre-fixed with glutaraldehyde which limits their deformability in the multilayer. The templating process with PDMS practically casts only the shape of the top cell layer and the presence of other cells underneath has no effect on the shape of produced imprints. This simplifies the process as it does not require fabrication of a perfect cell monolayer.
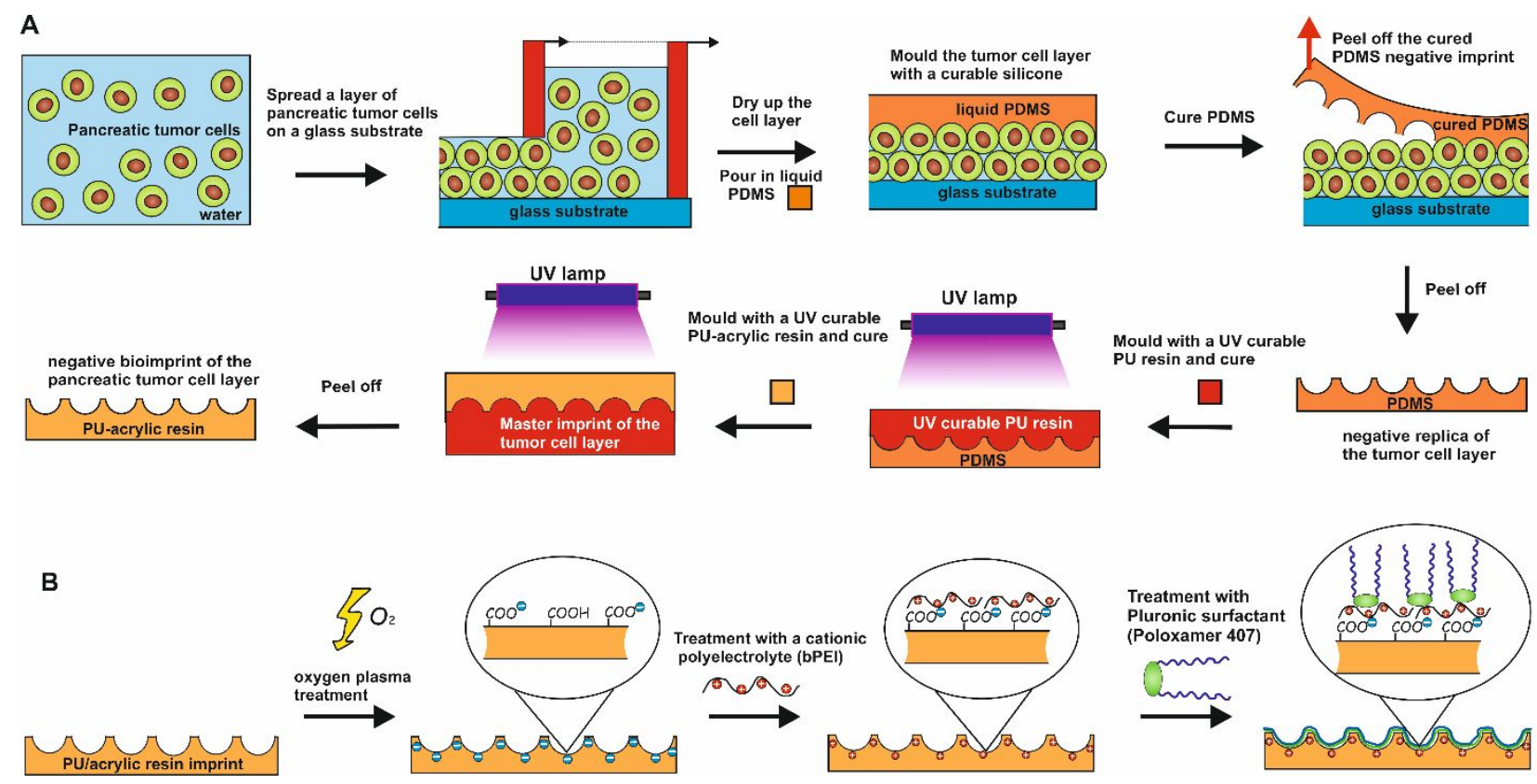

Figure 3. (A) Schematic of the preparation of cell imprints using a layer of pancreatic tumor cells templated with curable silicone. The bioimprint retains information about the blood cancer cells shape and morphology, can be reproduced on a large scale and used in pancreatic tumor cell concentrator device for early detection of pancreatic cancer. (B) Surface treatment of the pancreatic tumor cell bioimprints by oxygen plasma and surface modification with a cationic 
polyelectrolyte allows us to promote adhesion between the bioimprint and the shape matching tumor cells.

Figure 3B illustrates the surface treatment of the negative bioimprints before being used in the flow-through chip. The imprint was surface oxidized with oxygen plasma to create abundant carboxyl groups $(-\mathrm{COOH})$ on its surface which then serve as anchoring points of a cationic polyelectrolyte (branched polyethylene imine, bPEI). The purpose of this treatment was to engineer a weak electrostatic attraction between the imprint surface and the negatively charged cells (PBMCs and CTCs). Although curable PDMS has a good resolution to retain the molded shape of the cell layer, it has very poor retention of any surface groups like $\mathrm{COOH}$, resulting from surface oxidation. The reason is the inherent fluidity of the silicone chains trapped in the 3D network of the cured PDMS, leading to gradual transfer of $\mathrm{COOH}$ groups from the surface to the bulk. It has been reported that surface oxidised PDMS increases its contact angle over the course of several hours $[60,61]$. This is why we use PU resin replica which preserves its surface properties after surface oxidation due to the rigid 3D structure of this polymer. In addition the PU resin is harder than the PDMS which helps with the replication process.

To prevent both types of cells from coming too close to the imprint and becoming trapped by the van der Waals attraction, we treated the bPEI coated imprint with an additional layer of Pluronic surfactant (Poloxamer 407) which minimizes non-specific attachment of the cells to the imprint $[28,29]$. The effect of the Poloxamer 407 treatment is not related to changing of the wettability of the bioimprint surface rather than off-setting the cells from the surface which prevents non-specific adhesion $[28,29]$. The idea behind this combination of treatments is that when the approaching cells match closely the imprint cavities, the weak electrostatic attraction is amplified by the large area of contact with the imprint cavity. For PBMCs, which do not closely fit in the cavities and make only a point contact, the subsequent flushing step allows their 
removal from the imprint while the CTCs remain on the imprint and concentrate on its surface, which facilitates their detection.

\subsection{Bioimprint microscopy characterization}

As the cell dimension analysis appeared ideal for bioimprint separation the tumor cells were used to create a bioimprint as a negative replica of the top surface of a layer of tumor cells. Figure S1A,B (Supporting Information) shows the initial cell layer of ASPC-1 cells before the replication process. A PDMS replica of this layer was produced. The cell layer remained mostly intact (Figure S1D) after replication with PDMS (Figure S1C) as most cells remained attached to the glass substrate due to the adhesion of the glucose and xanthan gum additives. The negative PDMS imprint in turn was then used to create a positive master PDMS imprint (Figure 4A,B). From this master imprint, multiple copies could be made using UV curable PU resin and these were then analyzed and used in our experiments. Analysis showed that there was no significant loss of quality of the bioimprint from the first negative (Figure 4A) to the consecutive negative imprints (Figures 4E, F) taken by templating the master positive imprint (Figure 4B, 4C) on PDMS and the one based on PU-resin on PET foil (Figure 4D).

Figure S2 (Supporting Information) shows further optical microscopy images of the negative and positive imprints of ASPC-1 cell layers which indicated a good quality of the replication process. Figure S8 shows more SEM images of ASPC-1 negative imprints on PU resin copied from a PDMS positive imprint of a layer of the same cells. Figure S3 shows similar quality of the replication of Mia-PaCa-2 cell layers by PDMS as negative (Figure S3A), positive master (Figure S3B) and negative imprints on PU resin on PET foil, which was used in our experiments. Figure S4 shows SEM images of consecutive negative replicas of the master PDMS imprints indicating that multiple negative imprints can be taken without loss of quality or resolution.

\subsection{Bioimprint cell selectivity}


A series of experiments was undertaken to determine the bioimprint cell selectivity for the target tumnour cells within a mixed cell population. To investigate the capture efficiency of pancreatic tumour cells a series of ASPC-1 or MiaPaCa-2 cell concentrations were added to healthy human (PBMC) to create a mixed cell population. Firstly, the capture of ASPC-1 cells on an ASPC-1 bioimprint was investigated. The capture efficiency (percentage of ASPC-1 retained on the bioimprint with respect to the PBMC population) was observed to be proportional to the initial percentage of ASPC-1 cells in the mixed ASPC-1/PBMC cell population.
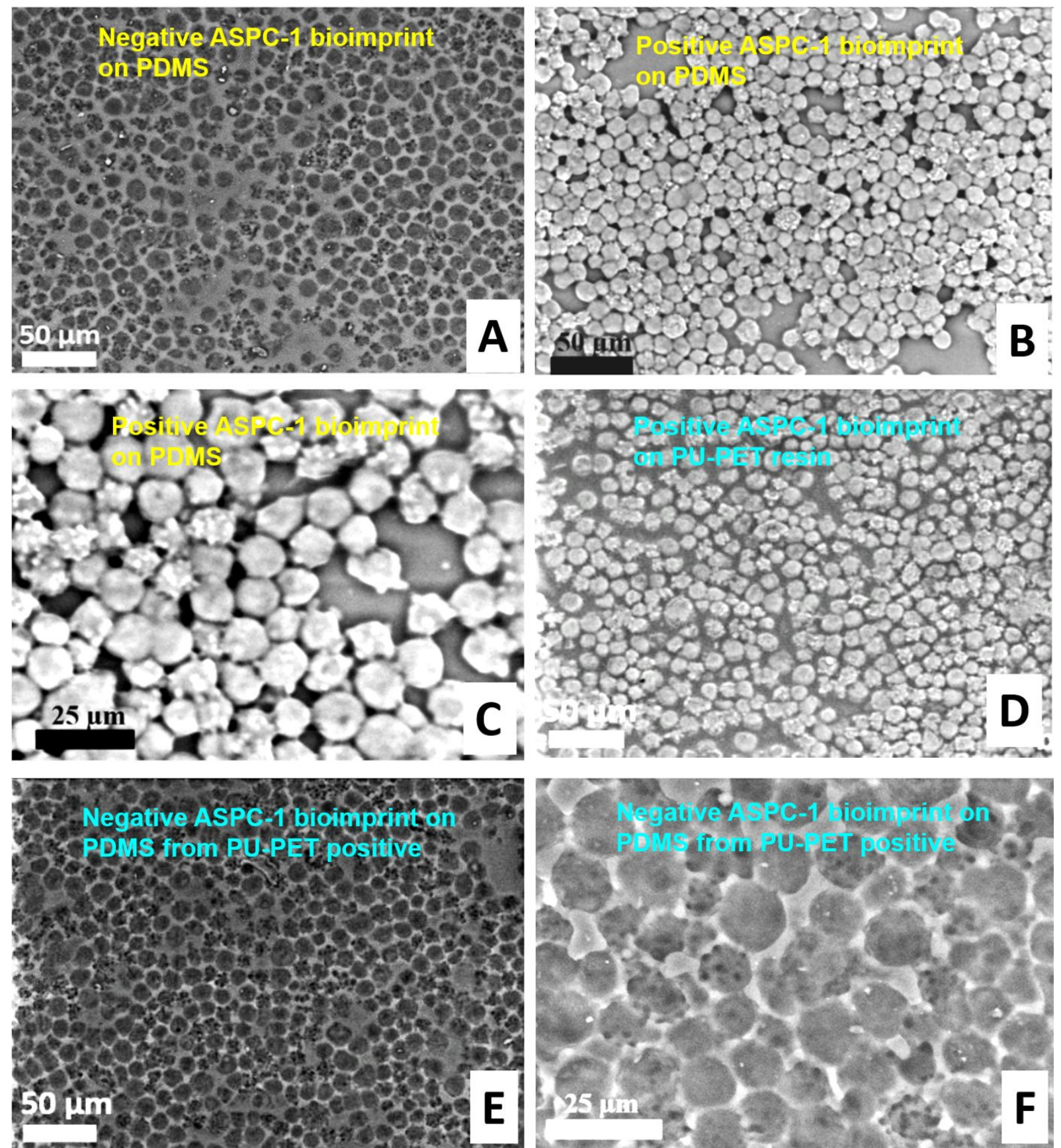
Figure 4. SEM image of the PDMS negative bioimprint of ASPC-1 cell layer (A). SEM images of the PDMS positive bioimprint of ASPC-1 cell layer at different resolutions (B,C). SEM image of the positive ASPC-1 bioimprint on PU-resin on PET foil (D) copied from the negative PDMS bioimprint (A). SEM images of a negative PU resin on PET bioimprint at different resolutions (E,F) copied from the positive PDMS bioimprints $(\mathrm{B}, \mathrm{C})$.

Figure 5A and 4C show flourescence microsopy images after seeding of a 1\%:99\% ASPC-1:PBMC cell mixture on the bioimprint chip. Figures 5B and 5D show the retained PBMC and ASPC-1 cells after incubation and flushing with $150 \mathrm{~mL} \mathrm{~h}^{-1} \mathrm{PBS}$. Data obtained with single seeding at $1 \%$ ASPC-1 initial concentration showed that only $\sim 30 \%$ of the initial amount of tumor cells were retained on the bioimprint chip after the flushing step. However, at 5\% ASPC-1, neary $90 \%$ of the tumor cells were retained on the imprint after a single seeding on the chip (Figure 5E). At 1\% initial ASPC-1 concentration with respect to the PBMCs, the retained ASPC-1 cells on the ASPC-1 imprint were equivalent to a 30 -fold amplification (Figure 5F). 

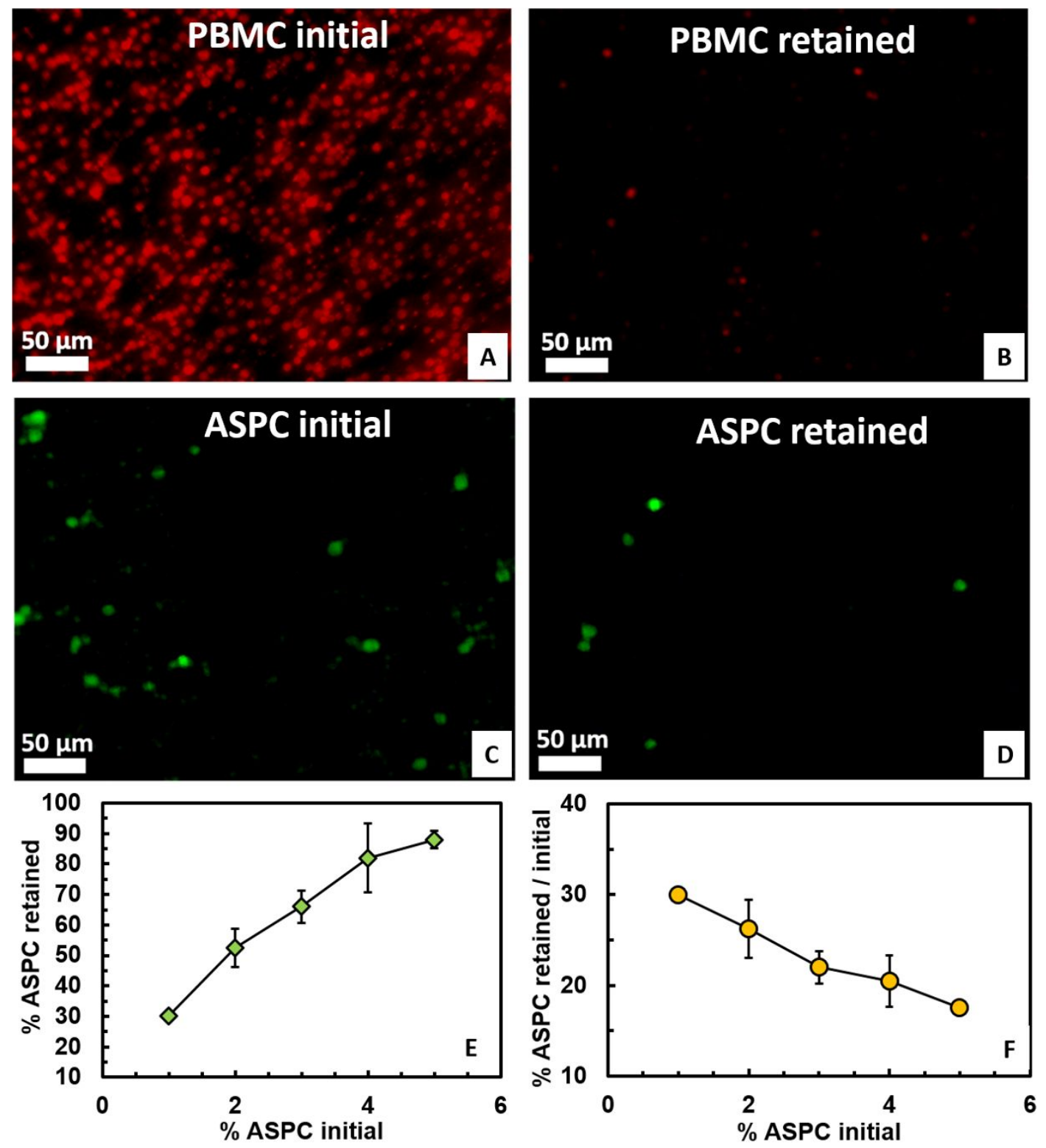

Figure 5. Fluorescence microscopy images of lissamine-rhodamine stained PBMC on an ASPC-1 PU negative bioimprint at time of seeding (A) and after flushing with PBS (B). Fluorescent microscopy images of carboxyfluorescein-lipid stained ASPC-1 cells on an ASPC-1 PU bioimprint at time of seeding (C) and after washing (D). The percentage of retained ASPC-1 cells with respect to the PBMC (E) and (F) with respect to the initial percentage of ASPC-1 cells versus the percentage of ASPC-1 cells in the initial seeding mixture. Each data point is an average of at least 2 repeats. Pearson's rank correlation coefficient (r) was 0.98 (E) and -0.99 (F).

SEM images captured after the retention experiments showed the larger tumour cells and PBMC clearly retained on the bioimprint. Figure 6 presents SEM images of the ASPC-1 bioimprint after seeding with a 5\%:95\% ASPC:PBMC mixture and after flushing with PBS at $150 \mathrm{~mL} \mathrm{~h}^{-1}$. 


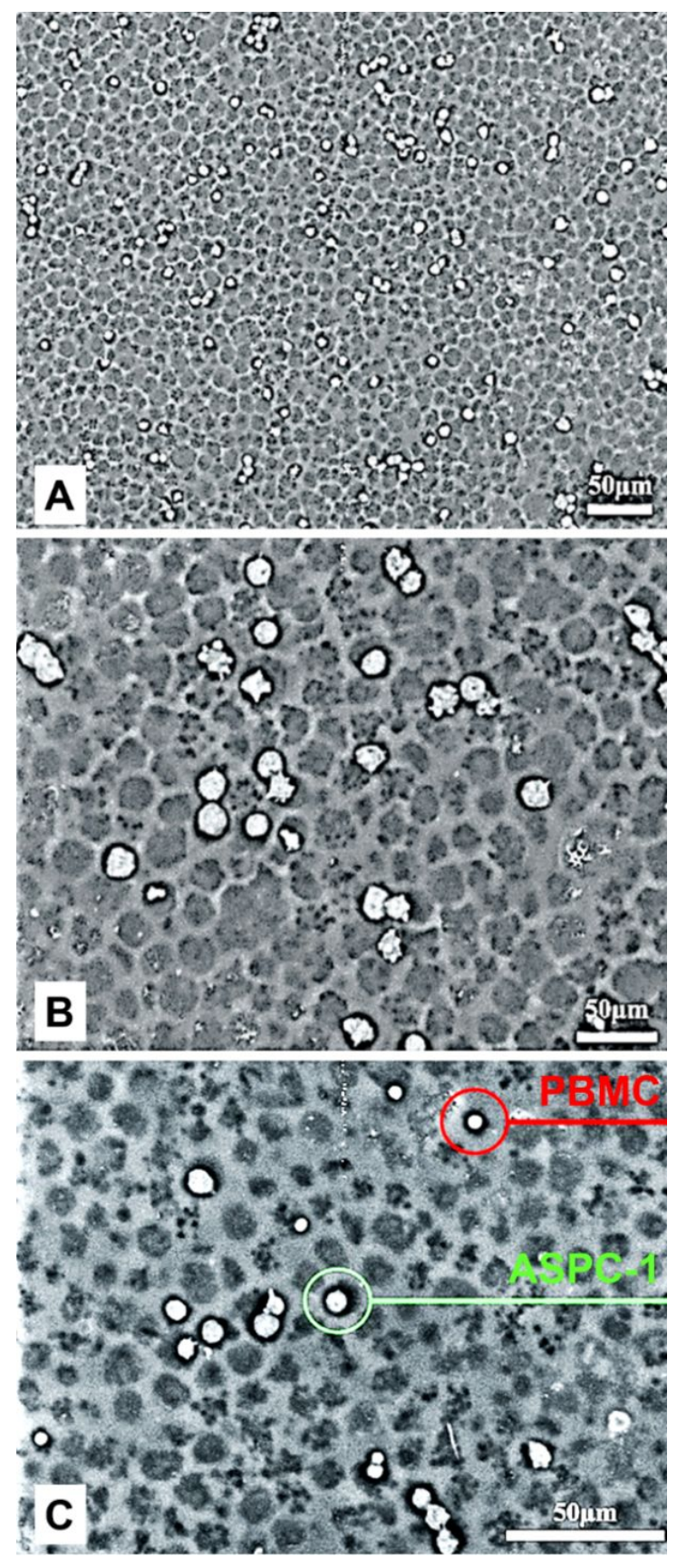

Figure 6. SEM images of ASPC-1 cell bioimprint after incubating with PBMC:ASPC-1 cell mixture under static conditions. Non-bound cells were flushed from the surface by PBS buffer at fixed flow rate of $150 \mathrm{~mL} \mathrm{~h}^{-1}$ which selectively washes the PBMCs. The SEM images were taken after drying at different resolutions (A, B). Note the difference is size and morphology of the ASPC-1 cells and the PBMCs (even after shrinking during the drying process for SEM sample preparation $(\mathrm{C})$.

One can see that although the cells have partically shrunk due to drying during the the sample preparation for SEM, there are clear morphological and size differences between the tumor cells and the PBMCs and that the former represent a better fit within the bioimprint cavities. It is 
perceived that the increased area of contact between the matching tumor cells and the imprint surface makes them more strongly attached to the bioimprint and thus allows them to be retained on the chip after the flushing step. This depletes a much higher fraction of PBMCs leading to effective concetrating of the captured tumor cells in proportion to the PBMCs on the bioimprint. Multiple seedings of different types of tumor cells on the ASPC-1 and MiaPaCa-2 bioimprints were assesed to ascertain whether this would result in capture of more tumour cells. The data in Figures 7A obtained on ASPC-1 bioimprint suggests a gradual increase from $34 \%$ to $55 \%$ in the retained cell ratio of ASPC-1:PBMC with multiple seedings again showing an amplification of the target tumor cell population.

A gradual decrease in the retained PBMCs percentage on the imprint was observed with each seeding and the ASPC-1 bioimprint was enriched with tumor cells (Figure 7B). The trend was even stronger for Mia-PaCa-2 cells on Mia-PaCa-2 bioimprint (see Figure 7C and 7D). To further assess the selectivity of the larger tumour cells over PBMCs, Mia-PaCa-2 cells were seeded onto the ASPC-1 bioimprint and the data obatined were shown to be similar (Figure 7E,F). Interestingly, the seeding of Mia-PaCa-2:PBMC cell mixture on ASPC-1 bioimprint produced very similar results as ASPC-1:PBMC mixture on ASPC-1 bioimprint (Figure 7A,7B) with an initial retention ratio of $28 \%: 72 \%$ of Mia-PaCa-2:PBMC, increasing to $52.5 \%: 47.5 \%$ after the 5th seeding. Since ASPC-1 and Mia-PaCa-2 are geometrically and morphologically very similar (see Table 1 and Figure 2) one would expect that the bioimprint, produced from one pancreatic tumor cell line could be effective for capturing other pancreatic CTCs of the same geometry and morphology. This presents an opportunity to produce a generic bioimprint from a primary or secondary tumor cell line which can be applied for isolation of CTCs from blood samples. 
$0.5 \%$ ASPC on ASPC bioimprint
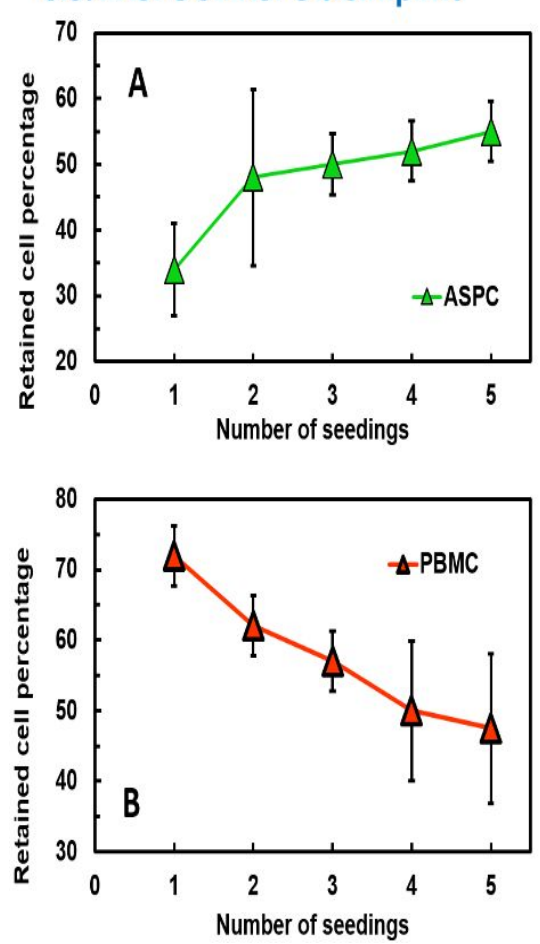

$0.5 \%$ MIAPACA on MIAPACA bioimprint
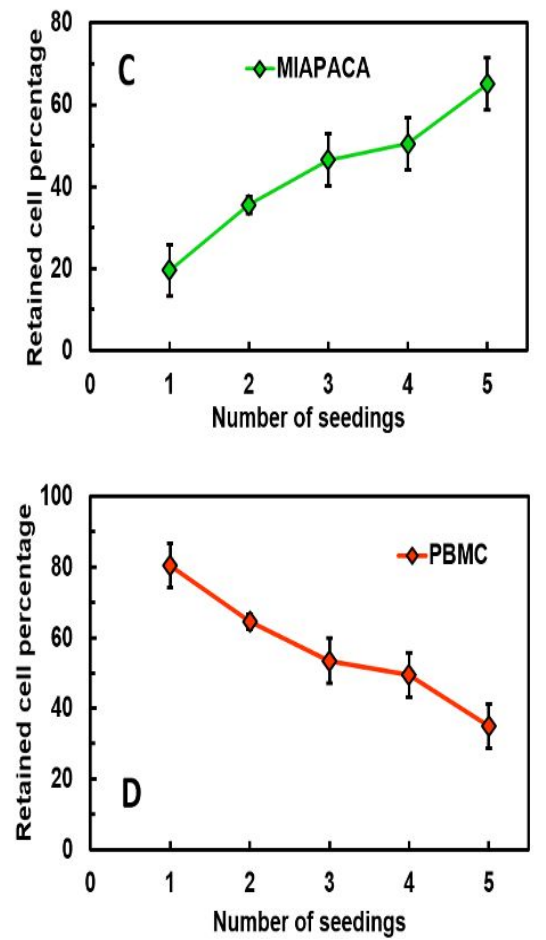

$0.5 \%$ MIAPACA on ASPC bioimprint
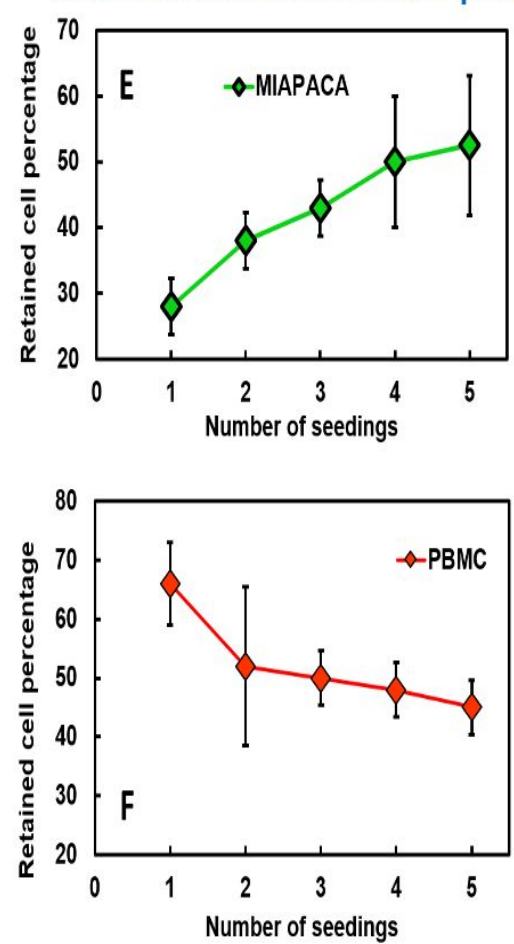

Figure 7. (A) ASPC-1 cells and (B) PBMCs retention on an ASPC-1 bioimprint in relation to the number of individual seedings of the cell mixture on the bioimprint. The seeding cell ratio in (A,B) was 0.5\% ASPC-1:99.5\% PBMC. (C) Mia-PaCa-2 cell and (D) PBMC retention on an Mia-PaCa-2 bioimprint in relation to the number of individual seedings of the cell mixture on the bioimprint. (E) Mia-PaCa-2 cells and (F) PBMCs retention on an ASPC-1 bioimrpint as a function of the number of individual seedings of the cell mixture on the bioimprint. The seeding cell ratio in (C-F) was 0.5\% Mia-PaCa-2:99.5\% PBMC. Each data point is an average of at least 2 repeats. Pearson's rank correlation coefficient (r) was 0.89 (A), -0.89 (B), 0.98 (C), -0.98 (D), $0.98(\mathrm{E})$ and $-0.98(\mathrm{~F})$.

Althougth the bioimprint chip is far from optimized to be a direct CTCs early detection tool, these results are very encouraging and when used with a CTC enrichment step could allow for liquid biopsy analysis from patient samples and increase the likelihood for early detection of the primary tumor. Figure $8 \mathrm{~A}, 8 \mathrm{~B}$ shows the effect of the interchangeability of the type of the pancreatic tumor imprint on its capture efficiency. The images show the effect of multiple seedings of a mixture of Mia-PaCa-2:PBMC cell mixture $(0.5 \%: 99.5 \%)$ on the retained cells after flushing of the bioimprint chip with PBS. Note that the percentage of decrease of the initially seeded tumor cells after flushing initially decreases with the number of seedings from $55 \%\left(1^{\text {st }}\right.$ seeding) to $26 \%$ ( $3^{\text {rd }}$ seeding) but then it plateaus after the $3^{\text {rd }}$ seeding with the cell 
mixture (Figure $8 \mathrm{C}$ ). Note that accumulation of the Mia-PaCa-2 cells during this process, as presented in Figure 7E.
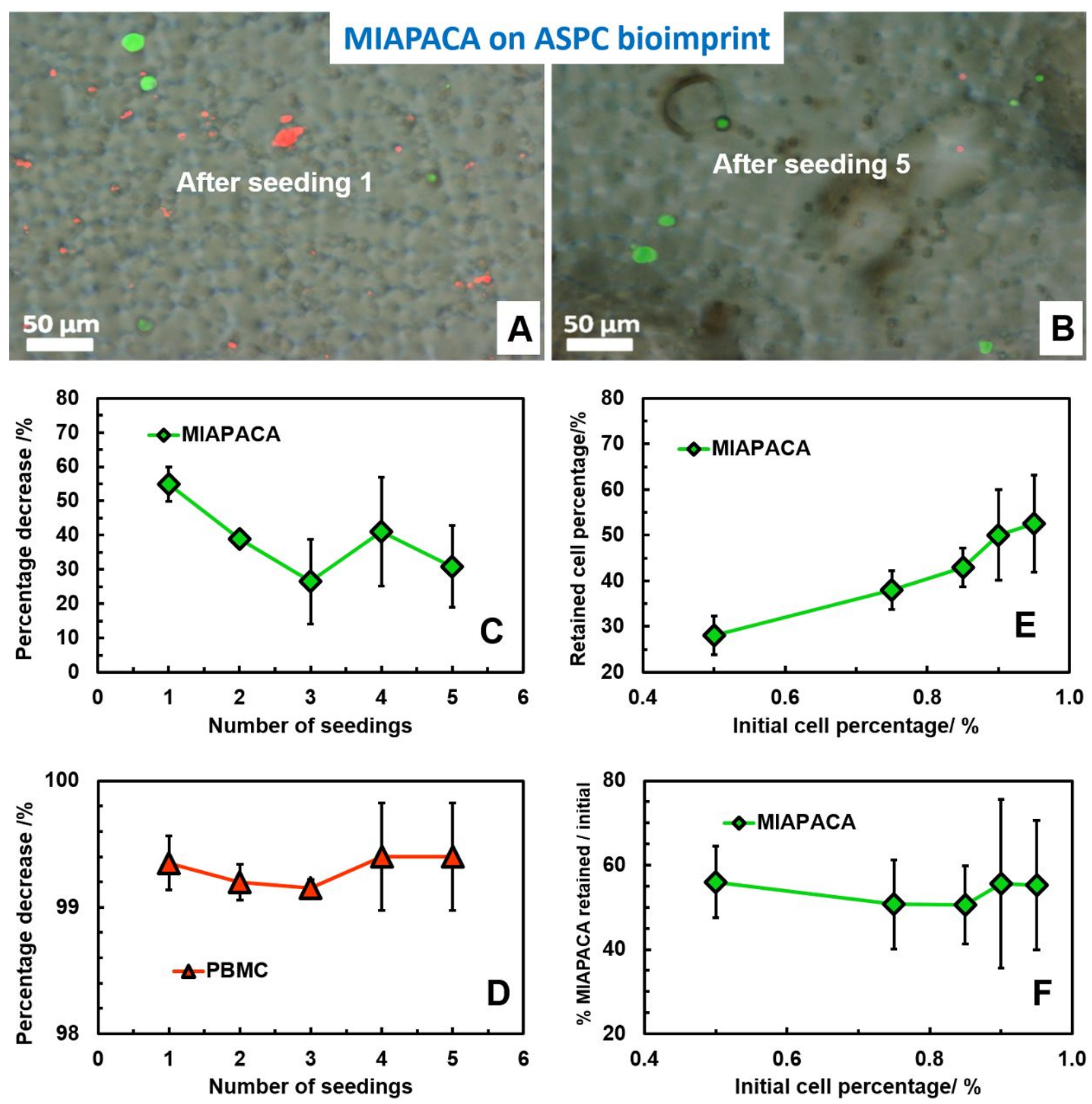

Figure 8. Fluorescence microscopy image of a mixture of $0.5 \% \mathrm{Mia}-\mathrm{PaCa}-2$ and $99.5 \% \mathrm{PBMC}$ on ASPC-1 bioimprint after the $1^{\text {st }}$ seeding (A) and after the $5^{\text {th }}$ seeding (B) followed flushig of the chip with PBS at $150 \mathrm{~mL} \mathrm{~h}^{-1}$. The fluorescence microscopy images are superimposed on the brightfield images of the ASPC-1 bioimprint. The corresponding percentage of decrease of Mia-PaCa-2 cells (C) and PBMCs (D) in relation to the number of individual seedings of the cell mixture on the ASPC-1 bioimprint. The seeding cell ratio in (A,B,C,D) was $0.5 \%$ ASPC-1:99.5\% PBMC. The retained percentage of Mia-PaCa-2 cells (with respect to the PBMCs) as a function of the initial cell percentage $(E)$. The relative percentage of ine initial Mia-PaCa-2 cells retained as a function of the initial cell percentage seeded on a ASPC-1 
bioimrpint (F). Pearson's rank correlation coefficient (r) was -0,66 (C), $0.01(\mathrm{D}), 0.98$ (E) and $0.14(\mathrm{~F})$.

We did not detect a measurable effect of the seedings on the percentage decrease PBMCs, which was consistently high for all seedings ( $99.5 \%)$, indicating that PBMCs are not preferentially retained on the ASPC-1 imprint (Figure 8D). Increasing the initial Mia-PaCa-2 cell percentage generally led to an increase of the percentage of cells retained on the imprint (Figure 8E). We found that this increase is in fact proportional to the initial percentage of tumor cells as the ratio of the percentage of the retained Mia-PaCa-2 cells towards their initial percentage (with respect to the PBMCs) does not change (Figure 8F). Additional data for the percentage of decrease and retention data for ASPC-1 on ASPC-1 imprint are Mia-PaCa-2 on ASPC imprint are presented in the Supporting Information (Figures S6 and S7), respectively. These results warrant discussion. A recently developed technique of automated filtration of CTCs based on size and using cytokeratin staining as a detection marker has been reported [16] where $42 \%$ of pancreatic cancer patients had detectable CTCs.

Similar to our methodology the authors spiked in vitro cultured pancreatic tumor cells into test samples. Firstly they used whole blood and then separated the PBMC/CTCs by Ficoll density gradient centrifugation, which the authors noted caused a loss of CTCs compared to spiking into PMBCs after isolation from blood. As a result they then used an apheresate from healthy donors and spiked in tumor cells. EpCAM was noted as not being useful for detection of CTCs in pancreatic cancer in the study.

Most CTCs isolation methods do rely on enrichment via label-dependent methods, which require expensive antibodies [17]. For example, a recent study used three EpCAM expressing tumour cell lines of different tumours (Prostate; PC3, breast; MCF-7 and pancreatic; T24) for surface replication [51]. When the surface was modified to include an anti-EpCAM antibody the capture efficiency was improved over an unmodified surface. However, as previously stated 
pancreatic cancer patient CTC samples may not express EpCAM and therefore its potential use as a target from patient samples may be limited. Their results also suggested that the cancer cells did not preferentially bind to their own replica imprints, as also shown here. A further study from the same group [52] utilised pollen grains to produce a PDMS imprint surface, again modified to include an anti-EpCAM antibody. This imprint was found to be efficient for capturing EpCAM positive MCF-7 and PC-3 cells but not EpCAM negative HeLa, Jurkat or Daudi cells suggesting the use of EpCAM was crucial to cell capture unlike in the present study where imprinted cell morphology and chemical surface modification was used to effectively target tumour cells over non-tumour cells. A further study, utilising cell imprinted gelatin substrates also used EpCAM to capture MCF-7 cells selectively [53]. To functionalise the imprint surface however, is costly but could also lead to further discrimination between tumour and non-tumour cells.

Other methods are label-free such as bioimprinting and filtration methods which have the advantage of simplicity and lower cost. Out of all these current methods, only bioimprinting can mimic the target cell morphology in a precise manner, while other techniques rely on filtration pore size and cell deformability to achieve enrichment. Gao et al have previously demonstrated, using PDMS imprints of a breast cancer cell line (MCF-7) that imprints not only accurately mimicked cell morphology but the cell-imprinted PDMS surface also retained proteins originating from the extracellular matrix. These motifs could then become artificial receptors which improve the target cell retention on the imprint, by enabling adhesion of the targeted cells [54]. To ascertain whether the imprints produced here can act in such a way could be further investigated using ligands to cell surface receptors and assess any specific binding. Previously, Imprinting bacteria in a principle as used here led to selectivity primarily via chemical recognition [55](ACS nano 2012,6,4314) 
The limitations with the presented bioimprint-based technique include a pre-purification step to isolate the PBMCs from whole blood which, as discussed above may not isolate all CTCs present although the clinical potential is clear from the results obtained within the study. Furthermore, there is the possibility that the imprints produced may capture other tumour cells which may pave the way for a more universal tumour imprint which would greatly enhance the potential in both research and clinical practice. This universality has been investigated recently with promising results small 2020 [56].

\section{Conclusions and future outlook}

The objective of the present study was to create generic pancreatic tumor bioimprints and test these for selectivity of the target tumor cells over healthy human blood cells (PBMCs). In summary, we designed and manufactured a pancreatic tumor cell bioimprint from two different cell lines (primary and secondary tumors) and demonstrated that both of them are capable of isolating and enriching pancreatic tumor cells from healthy white blood cells. The simplicity of the principle of tumor CTC isolation via morphological differences with circulating healthy blood cells has been studied previously via filtration techniques but here we report selective capture based on cell mimicry enhanced by bioimprint surface modification. The methodology established is robust and reproducible and allows for multiple replica bioimprints to be created from a single master bioimprint. Cell retention favored the target tumor cells over PBMCs due to the match of their cell size and morphological properties with the bioimprint cavities. We found that bioimprints from Mia-PaCa-2 (primary tumor) cell line and ASPC-1 (secondary tumor) cell line are interchangeable and allow selective capture of the two types of tumor cells. The increase of the number of seedings increase the CTCs capture efficiency. Tumor cell retention percentage over multiple seeding showed the ratio of tumor cell to PBMC being retained passed $50 \%$ in both ASPC-1 and Mia-PaCa-2 after 5 seedings onto an ASPC-1 bioimprint. Considering the starting ratio was only $0.5 \%$ tumor cells to $99.5 \%$ PBMC in order to 
be physiologically relevant, this amplification of over 50-fold enables the efficient detection of low numbers of tumor cells from a mixed cell population. Cells were fixed prior to use on the imprint but there is no reason why cells obtained from patient liquid biopsies could not also be fixed prior to analysis.

The method could be further developed into a clinically relevant early detection tool. The cells that are captured from bioimprint based liquid biopsy can be further analyzed either with fluorescently tagged antibodies or genetically analyzed on the imprint via techniques such as in situ fluorescent hybridization (FISH). Recent advances in FISH probes resulted in 93\% sensitivity and $100 \%$ specificity in detecting cancer cells in pancreatobiliary tissue [57]. Another FISH analysis on isolated CTC showed a sensitivity of $88 \%$ and specificity of $90 \%$ for pancreatic cancer when cells were stained with a combination of markers [58].

A high-throughput cell screening platform could therefore be developed which could allow large areas of the bioimprint surface to be imaged and captured tumor cells interrogated. The preparation of a generic bioimprint from pancreatic CTCs can be done on a very large scale in a standardized way using Roll-to-Roll Nanolithography [59] as recently done by Das et al.[28] for human leukemic cells, which would allow cheap fabrication of bioimprint based screening tools for detection or analysis of pancreatic tumor CTCs. Further work should also be undertaken to ascertain whether CTCs from tumors of multiple origins could also be captured on a single, universal tumor imprint which would substantially impact CTC detection capability.

\section{Experimental Section}

\subsection{Human cells culturing and fixation}

Pancreatic tumor cells (ASPC-1 and Mia-PaCa-2) were sourced from Public Health England. ASPC-1 cells were cultured in RPMI medium (Lonza, UK) while Mia-PaCa-2 were grown IMDM media, both supplemented with $10 \% \mathrm{v} / \mathrm{v}$ fetal bovine serum (Labtech, UK) and 
penicillin/streptomycin $\left(1 \% \mathrm{v} / \mathrm{v}\right.$, Lonza, UK) within a humidified $37^{\circ} \mathrm{C}$ incubator in the presence of $5 \% \mathrm{CO}_{2}$. Cells were harvested when at least $70 \%$ confluency had been achieved. Human PBMCs were obtained from the National Blood Transfusion Service (UK) from anonymous healthy donors with ethical approval REC 16/LO/1948 (under IRAS 214660) [47] and stored in liquid nitrogen prior to use. Cells were fixed with the dropwise addition of $2.5 \% \mathrm{v} / \mathrm{v}$ glutaraldehyde in phosphate buffered saline (PBS) to concentrated cell suspensions for $15 \mathrm{~min}$. Cells were then washed twice with PBS and finally re-suspended in PBS at appropriate concentrations. Cells were counted with a Neubauer haemocytometer.

\subsection{Preparation of $\mathrm{ASPC}-1$ and Mia-PaCa-2 negative and positive bioimprints}

The glass substrate $(20 \mathrm{~cm} \times 20 \mathrm{~cm} \times 0.5 \mathrm{~cm})$ was carefully washed with ethanol, distilled water and soap. Once dried, a $10 \mathrm{wt} \%$ of $\mathrm{KOH}$ solution in ethanol was then distributed uniformly on the clean glass for complete degreasing for $1 \mathrm{~h}$. The glass was washed with deionized water and dried. $1 \mathrm{wt} \%$ PDAC solution was poured on the glass substrate, spread evenly over the surface and incubated for $2 \mathrm{~h}$. The treated glass was washed again with distilled water to remove the excess of PDAC and dried under air in a laminar flow hood for $30 \mathrm{~min}$. The fixed cell suspension in PBS we centrifuged and $1 \mathrm{~g}$ of the pellet with the cells (wet weight) was added to a solution containing $0.4125 \mathrm{~g}$ of glucose and $2 \mathrm{~mL}$ of gum xanthan $(0.1 \mathrm{wt} \%)$ in deionized water under stirring. The final mixture was spread evenly on the glass using a customized glass spreader [28] and left to dry within a laminar flow hood for $30 \mathrm{~min}$. The glass was then coated with PDMS (Sylgard 184, Dow Corning, 10:1 elastomer:cross-linker ratio) using a customized square metal frame $(15 \mathrm{~cm} \times 15 \mathrm{~cm})$ to contain the molding material and was covered and dried at room temperature overnight. The PDMS negative imprint was detached from the glass with a scalpel and washed with ethanol, distilled water and then a soap solution. Negative bioimprints were made either on PDMS or by using UV curable polyurethane (PU) resin or JR15 acrylic 
resin on PET foil. JR15 is a proprietary UV curable acrylic resin (Joanneum Research FmbH, Graz, Austria). To create a master positive imprint a square of the negative PDMS imprint was cut out with a scalpel, carefully washed with ethanol, distilled water, soap and dried. A solution of $0.1 \mathrm{wt} \%$ HPMC in sodium dihydrogen orthophosphate buffer $(5 \mathrm{mM}, \mathrm{pH} 3)$ was spread on the imprint surface. After $1 \mathrm{~h}$, the imprint was washed with deionized water and dried. Then, the base of the imprint was attached on glass support with double sided tape. The glass was coated with $25 \mathrm{~mL}$ of PDMS and cured at room temperature with a cover during $24 \mathrm{~h}$. The positive and negative bioimprint are then separated from one another. A schematic of the process is shown in Figure 3.

\subsection{Fabrication of multiple negative bioimprints from positive replica}

The positive bioimprint with PDMS was carefully washed with ethanol, distilled water, soap and dried. A solution of HPMC $0.1 \mathrm{wt} \%$ in sodium dihydrogen orthophosphate buffer $(5 \mathrm{mM}, \mathrm{pH} 3)$ was spread on the imprint. After $25 \mathrm{~min}$, the imprint is washed with distilled water and dried. 1

$\mathrm{mL}$ of a $10 \%$ thiol (trimethylpropanate tris (3-mercapto propionate)) solution in polyurethane resin was spread on a PET foil. This solution is also spread on the positive bioimprint. The foil was carefully placed on top of the imprint and a scraper was used to evacuate trapped air bubbles. A glass panel was clipped on the top of the PET foil on the imprint and the resin was cured under UV light (Portable UV lamp, $365 \mathrm{~nm}, 10 \mathrm{~W}$ ) for $1 \mathrm{~h}$. The PET foil with the imprint replica was detached from the templated imprint. Images were taken from the imprint samples with optical microscopy (Olympus BX-51). Scanning electron microscopy (SEM) images were produced after coating of the specimens with a $10 \mathrm{~nm}$ carbon layer.

\subsection{Cell staining for bioimprint selectivity experiments}

In order to differentiate between the tumor cells (ASPC-1 or Mia-PaCa-2) and the PBMCs, all cells were fluorescently tagged before mixing with other cell populations: $10 \mathrm{~mL}$ of fixed cells were collected by centrifugation $3 \mathrm{~min}$ at $400 \mathrm{~g}$. The supernatant was discarded and $10 \mathrm{~mL}$ of 
distilled water was added. This operation was repeated twice to wash the cells, the supernatant was thrown after the last centrifugation and $5 \mathrm{~mL}$ of deionized water was added. The tube was then placed in an ultrasonic bath for 5 min to avoid cell aggregation. $500 \mu \mathrm{L}$ of ethanol solution of 1,2-dioleoyl-sn-glycero-3-phosphoethanolamine-N (carboxyfluorescein) $\left(0.5 \mathrm{~g} \mathrm{~mL}^{-1}\right)$ was added dropwise in the $10 \mathrm{~mL}$ tumor cell suspension under agitation to fluorescently stain the cells in green, detectable with FITC fluorescence filter set. $500 \mu \mathrm{L}$ of lissamine-rhodamine $(0.5$ g $\mathrm{mL}^{-1}$ in ethanol) was used for PBMCs to fluorescently stain them in red, detectable with TRITC filter set. After $15 \mathrm{~min}$, the solution was centrifuged $5 \mathrm{~min}$ at $500 \mathrm{~g}$. The supernatant was discarded and $5 \mathrm{~mL}$ of deionized water was added. The tube was then placed in an ultrasonic bath for $5 \mathrm{~min}$. A new cell counting of the fluorescently tagged cells was made to determine the concentration. All cell suspensions were kept in a fridge at $4{ }^{\circ} \mathrm{C}$ in enclosed flasks wrapped with aluminum foil until further use in the experiments as described below.

\subsection{Bioimprint chip preparation}

To fabricate the bioimprint chip chamber, two stripes of plastic foil $(0.6 \mathrm{~cm} \times 5 \mathrm{~cm} \times 100 \mu \mathrm{m})$ were cut and stacked with a double-sided adhesive tape to form a template for a channel of combined thickness of $250 \mu \mathrm{m}$. Such channel templates were then attached to the bottom of a square plastic dish, with at least $3 \mathrm{~cm}$ space between each other. $50 \mathrm{~mL}$ of degassed PDMS (Sylgard 184, 10:1 elastomer : cross-linker) was poured on top of these stripes followed by further desiccation to remove any trapped air bubbles. After curing, the PDMS layer was peeled off the plastic dish and cut in rectangular pieces of width $25 \mathrm{~mm}$ and length of $8 \mathrm{~cm}$, including the $5 \mathrm{~cm}$ channel as show in Figure 1E. Oxygen plasma was used to alter the hydrophobicity of the polymeric bioimprint. A negative PU-PET bioimprint of ASPC-1 or Mia-PaCa-2 was treated in an oxygen plasma cleaner for $3 \mathrm{~min}$. A solution of $0.015 \mathrm{wt} \%$ branched polyethylenimine (bPEI) in water was spread on the imprint. This cationic polyelectrolyte was used to promote adhesion of the negatively charged CTCs to the imprint surface. After 15 min of incubation, the 
coated imprint was washed with deionized water and dried. The PDMS channel of the flow-through device was perforated at both ends of the channel with a biopsy tool $(3 \mathrm{~mm})$ to form inlet and outlet. The PDMS channel (Figure 1E) was washed with ethanol, air dried and then treated in oxygen plasma for 2 min. Rectangles of negative ASPC-1 or Mia-PaCa-2 bioimprint $(0.6 \mathrm{~cm} \times 4.5 \mathrm{~cm})$ pre-treated as described above were cut and placed over the channel aperture and a microscope slide was used as base of the chip. The assembled PDMS channel and the glass slide were clamped together and left in the oven at $40^{\circ} \mathrm{C}$ for $30 \mathrm{~min}$ to seal (Figure 1E-F). The channel depth was measured to be approximately $250 \mu \mathrm{m} .100 \mu \mathrm{L}$ of $1 \mathrm{wt} \%$ Poloxamer 407 (POL 407) was injected in the inlet of the PDMS flow-through chip. After 30 min, the bioimprint chips were flushed with $10 \mathrm{~mL}$ of PBS by using a syringe pump with a flowrate of $219 \mathrm{~mL} \mathrm{~h}^{-1}$. At this step the local flow velocity was estimated to be $0.0406 \mathrm{~m} \mathrm{~s}^{-1}$ which corresponds to Reynolds number of 18.7 (i.e. laminar flow). We have already studied and discussed the flushing conditions of our setup elsewhere [28,29] which allowed us to optimize the parameters in terms of flow rate, volume of buffer flushed through the chip and the time so that we maximize the retention of the target cells with respect to the PBMCs. Here we have used these conditions without further optimization.

\subsection{Tests of bioimprint selectivity}

Different cells suspensions of pre-stained ASPC-1 (or Mia-PaCa-2) and PBMCs in PBS were prepared. Each sample of fixed PBMC:ASPC-1 cell ratio was repeated at least twice, and cells were placed in an ultrasonic bath for 5 min to avoid any aggregation of the cells before the experiments. Figure S5 (Supporting Information) shows the experiment a setup with chip and the adjacent syringe pump for flushing with PBS. $100 \mu \mathrm{L}$ of the mixed cell suspension was injected through the inlet. Chips were covered with aluminum foil for $30 \mathrm{~min}$ to prevent photobleaching. Microscopy images were taken using fluorescence filter sets FITC (ASPC-1 
cells) and TRITC (for PBMC). Chips were flushed with $10 \mathrm{~mL}$ of PBS by using a syringe pump with a flow rate of $150 \mathrm{~mL} \mathrm{~h}^{-1}$ and the effluent was discarded. The local flow velocity was estimated to be $0.0278 \mathrm{~m} \mathrm{~s}^{-1}$ which corresponds to Reynolds number of 12.8 (i.e. laminar flow). Microscopy images were taken on multiple areas on the bioimprint (at least 10 fields of view with both FITC and TRITC filter sets) after this step. Fluorescence microscopy images obtained were quantitatively analyzed using ImageJ software with the macro script as described in the Supporting Information for each filter set, separately. Cells were enumerated by dividing the area on the imprint occupied by the respective fluorescent color over the area per single cell of this type (PBMCs or ASPC-1 or Mia-PaCa-2) determined from the mean cell size (see Figure 2). The calculation of the percentage decrease of the respective type of cells after flushing of the chip and the percentage of retained cells are described in the Supporting Information. Experiments with multiple seedings were also undertaken where after each flushing step, a new seeding with the same cell mixture was made, flushed after $30 \mathrm{~min}$ of incubation on the bioimprint and fluorescence microscopy images were taken and analyzed.

\subsection{Statistical analysis}

Where appropriate statistical analysis was performed. Data is presented and analysed as mean $( \pm \mathrm{SD})$ from two independent repeat experiments $(n=2)$. Pearson's rank correlation coefficients

(r) were used to determine the extent of the relationships between seedings and cell counts and ratios of cells seeded to that retained. These were performed using the data analysis toolpack for Microsoft Excel v 16.27 for Mac.

\section{ORCID}

Anupam A.K. Das: $\quad$ 0000-0003-1948-8811

Leigh A. Madden: 0000-0002-1503-1147

Vesselin N. Paunov: 0000-0001-6878-1681 


\section{Supporting Information}

Supporting Information is available from the Wiley Online Library (enclosed).

\section{Acknowledgements}

MP acknowledges Ecole Nationale Superieure de Chimie de Rennes for the opportunity to complete this work and the support from the ERASMUS+ mobility grant. AAKD, LAM and VNP thank Cancer Research UK for the Pioneer Award funding and Higher Education Innovation Fund (UK) for supporting this work. We also thank Help for Health (Hull, UK, charity number 1091814) for partially supporting this research. We also thank P. Weldrick for his help in the preparation of the SEM samples in Figure S8 for imaging.

\section{Conflict of Interest}

The authors declare no conflict of interest. 


\section{References}

[1] A. Jemal, T. Murray, A. Samuels, A. Ghafoor, E. Ward, M.J. Thun, Cancer Statistics 2003, CA Cancer J. Clin., 2003, 53, 5.

[2] A. Jemal, R. Siegel, J. Xu, E. Ward, Cancer Statistics 2010, CA Cancer J. Clin., 2010, 60, 277.

[3] A. Jemal, R. Siegel, E. Ward, Y. Hao, J. Xu, M.J. Thun, Cancer Statistics 2009, CA Cancer J Clin., 2009, 59, 225.

[4] B. Gudjonsson, Cancer of the pancreas. 50 years of surgery., Cancer, 1987, 60, 2284.

[5] S. Pandol, M. Edderkaoui, I. Gukovsky, A. Lugea, A. Gukovskaya., Clin. Gastroenterol. Hepatol. 2009, 7, S44.

[6] A.F. Hezel, A.C. Kimmelman, B.Z. Stanger, N. Bardeesy, R.A. Depinho, Genes Dev. 2006, $20,1218$.

[7] Cancer Research UK; Pancreatic Cancer Mortality Statistics 2014.

[8] J. Ferlay, P. Autier, M. Boniol, M. Heanue, M. Colombet, P. Boyle, Ann Oncol. 2007, 18, 581.

[9] A. Jemal, R. Siegel, E. Ward, Y. Hao, J. Xu, M.J. Thun, CA Cancer J. Clin. 2008, 58, 71. Cancer Research UK, https://www.cancerresearchuk.org/health-professional/cancer-statistics/statistics-by-cancer-typ e/pancreatic-cancer

[11] K. Tjensvoll, O. Nordgård, R. Smaaland, Int. J. Cancer, 2014, 134, 1.

[12]. J. S. Ankeny, C.M. Court, S. Hou, Q. Li, M. Song, D. Wu, J.F. Chen, T. Lee, M. Lin, S. Sho, M.M. Rochefort, M.D. Girgis, J. Yao, Z.A. Wainberg, V.R. Muthusamy, R.R.Watson, T.R. Donahue, O.J. Hines, H.A. Reber, T.G. Graeber, H.R. Tseng, J.S. Tomlinson, British Journal of Cancer, 2016, 114, 1367.

[13]. M.R. King, Front Oncol. 2012, 2, 194.1. 
[14] S. Wang, K. Liu, J. Liu, Z.T. Yu, X. Xu, L. Zhao, T. Lee, E.K. Lee, J. Reiss, Y.K. Lee, L.W. Chung, J. Huang, M. Rettig, D. Seligson, K.N. Duraiswamy, C.K. Shen, H.R. Tseng, Angew. Chem. Int. Ed., 2011, 50, 3084.

[15] Z. Liu, W. Zhang, F. Huang, H. Feng, W. Shu, X. Xu, Y. Chen, Biosens. Bioelectron., 2013, 47, 113.

[16] N. Brychta, M. Drosch, C. Driemel, J.C. Fischer, R.P. Neves, I. Esposito, W. Knoefel, B. Möhlendick, C. Hille, A. Stresemann, T. Krahn, M.U. Kassack, N.H. Stoecklein, O. von Ahsen, Oncotarget. 2017, 8, 86143.

[17] J-S. Lee, S.S. Park, Y.K. Lee, J.A. Norton, S.S. Jeffrey, Mol. Oncol. 2019, 13, 1623.

[18] N. Malara, M.L. Coluccio, T. Limongi, M. Asande, V. Trunzo, G. Cojoc, C. Raso, P. Candeloro, G. Perozziello, R. Raimondo, S. De Vitis, L. Roveda, M. Renne, U. Prati, V. Mollace, E. Di Fabrizio, Small, 2014, 10, 4324.

[19] S. Nagrath, L.V. Sequist, S. Maheswaran, D.W. Bell, D. Irimia, L. Ulkus, M.R. Smith, E.L. Kwak, S. Digumarthy, A. Muzikansky, P. Ryan, U.J. Balis, R.G. Tompkins, D.A. Haber, M. Toner, Nature, 2007, 450, 1235.

[20] J.H. Myung, C.A. Launiere, D.T. Eddington, S. Hong, Langmuir, 2010, 26, 8589.

[21] J.H. Kang, S. Krause, H. Tobin, A. Mammoto, M. Kanapathipillai, D.E. Ingber, Lab Chip, 2012, 12, 2175.

[22] T. Yeo, S.J. Tan, C.L. Lim, D.P.X. Lau, Y.W. Chua, S.S. Krisna, G. Iyer, G.S. Tan, T.K.H. Lim, D.S.W. Tan, W-T. Lim, C.T. Lim, Sci. Rep., 2016, 6, 22076.1.

[23] E. Sollier, D.E. Go, J. Che, D.R. Gossett, S. O'Byrne, W.M. Weaver, N. Kummer, M. Rettig, J. Goldman, N. Nickols, S. McCloskey, R.P. Kulkarni, D. Di Carlo, Lab Chip, 2014, $14,63$.

[24] B.J. DiPardo, P. Winograd, C.M. Court, J.S. Tomlinson, Expert Rev. Molec. Diagn., 2018, $18,809$. 
[25] J. Medlock, A.A.K. Das, L.A. Madden, D.J. Allsup, V.N. Paunov, Chem. Soc. Rev., 2017, 46,5110 .

[26] J. Borovicka, S.D. Stoyanov, V.N. Paunov, Nanoscale, 2013, 57, 8560.

[27] J. Borovicka, W.J. Metheringham, L.A. Madden, C.D. Walton, S.D. Stoyanov, V.N. Paunov, J. Am. Chem. Soc., 2013, 135, 5282.

[28] A.A.K. Das, J. Medlock, H. Liang, D. Nees, D.J. Allsup, L.A. Madden, V.N. Paunov, J. Mater. Chem. B, 2019, 7, 3497.

[29] P. Remaud, J. Medlock, A.A.K. Das, D.J. Allsup, L.A. Madden, D. Nees, P.J. Weldrick, V.N. Paunov, Mater. Chem. Front., 2020, 4, 197.

[30] J. Borovicka, S.D. Stoyanov, V.N. Paunov, Phys. Rev. E., 2015, 92, 032730.1.

[31] F.L. Dickert, O. Hayden, Anal. Chem., 2002, 74, 1302.

[32] K. Eersels, P. Lieberzeit, P. Wagner, ACS Sens., 2016, 1, 1171.

[33] O. Hayden, P.A. Lieberzeit, D. Blaas, F.L. Dickert, Adv. Funct. Mater. 2006, 16, 1269.

[34] O. Hayden, R. Bindeus, F.L. Dickert, Meas. Sci. Technol. 2003, 14, 1876.

[35] O. Hayden, K.J. Mann, S. Krassnig, F.L. Dickert, Angew. Chem., Int. Ed. 2006, 45, 2626.

[36] N. Perez, C. Alexander, E.N. Vulfson, Surface imprinting of microorganisms Molecularly Imprinted Polymers Man-Made Mimics of Antibodies and Their Applications in Analytical Chemistry, Elsevier Science, Amsterdam, 2001, ch. 11, 295-303.

[37] D. Cunliffe, C. Alexander, In: Molecular Imprinted Polymers: Science and Technology, CRC Press, New York, 2002, 249.

[38] T. Cohen, J. Starosvetsky, U. Cheruti, R. Armon, Int. J. Mol. Sci., 2010, 11, 1236.

[39] M. Jenik, A. Seifner, S. Krassnig, K. Seidler, P.A. Lieberzeit, F.L. Dickert, C. Jungbauer, Biosens. Bioelectron., 2009, 25, 9.

[40] V.N. Paunov, O.J. Cayre, Adv. Mater., 2004, 16, 778.

[41] V.N. Paunov, Langmuir, 2003, 19, 7970. 
[42] Al-Shehri, H.; Horozov, T.S.; Paunov, V.N., Soft Matter, 2014, 10, 6433.

[43] V.N. Paunov, O.J. Cayre, , MRS Proceedings Fall, 2003, M8.25.1.

[44] K.M. Reed, J. Borovicka, T.S. Horozov, V.N. Paunov, K.L. Thompson, A. Walsh, S.P. Armes, Langmuir, 2012, 28, 7291.

[45] E.L. Sharp, H. Al-Shehri, T.S. Horozov, S.D. Stoyanov, V.N. Paunov, RSC Adv., 2014, 4, 2205.

[46] O.J. Cayre, V.N. Paunov, J. Mater. Chem., 2004, 14, 3300.

[47] REC reference:16/LO/1948, IRAS project ID: 214660, Dr David Allsup - Chief Investigator.

[48] A.D. Rhim, E.T. Mirek, N.M. Aiello, A. Maitra, J.M. Bailey, F. McAllister, M. Reichert, G.L. Beatty, A.K. Rustgi, R.H. Vonderheide, S.D. Leach, B.Z. Stanger, Cell, 2012, 148, 349.

[49] W.J. Allard, J. Matera, M.C. Miller, M. Repollet, M.C. Connelly, C. Rao, A.G. Tibbe, J.W. Uhr, L.W. Terstappen, Clin Cancer Res. 2004, 10, 6897.

[50] A. Mujahid, N. Iqbal, A. Afzal, Biotechnol. Adv., 2013, 31, 1435.

[51] W. Wang, H. Cui, P. Zhang, J. Meng, F. Zhang, S. Wang ACS Appl. Mater. Interfaces. 2017, 9, 10537.

[52] W. Wang, G. Yang, H. Cui, J. Meng, S. Wang, L. Jiang. Adv. Healthcare Mater. 2017, 6, 1700003.

[53] S-W. Lv, Y. Liu, M. Xie, J. Wang, X-W. Yan, Z. Li, W-G. Dong, W-H. Huang. ACS Nano. 2016, 10, 6201 .

[54] S. Gao, S. Chen, Q. Lu. Biomater. Sci., 2019, 7, 4027.

[55] K. Ren \& R.N. Zare. ACS Nano. 2012, 6, 4314

[56] L. Lie, C. Dong, X. Li, S. Li, B. Ma, B. Zhao, X. Li, Z. Liang, K. Yang, L. Zhang, Y. Zhang. Small 2020, 16. 1904199. 
[57] E.G. Barr Fritcher, J.S. Voss, S.M. Brankley, M.B. Campion, S.M. Jenkins, M.E. Keeney, M.R. Henry, S.M. Kerr, R. Chaiteerakij, E.V. Pestova, A.C. Clayton, J. Zhang, L.R. Roberts, G.J. Gores, K.C. Halling, and B.R. Kipp, Gastroenterology 2015, 149, 1813.

[58] Y. Gao, Y.Y. Zhu, Z.Z. Zhang, C. Zhang, X.Y. Huang, and Z. Yuan, J. Experim. \& Clin. Cancer Res., 2016, 35, 66.

[59] M. Leitgeb, D. Nees, S. Ruttloff, U. Palfinger, J. Götz, R. Liska, M.R. Belegratis, B. Tadlober, ACS Nano, 2016, 10, 4926.

[60] D.T. Eddington, J.P. Puccinelli, D.J. Beebe, Sens. \& Actuat. B: Chemical, 2006, 114, 170.

[61] T. Senzai, S. Fujikawa, Langmuir 2019, 35, 9747-9752. 